\title{
Testagem Rápida para COVID-19 em uma rede de farmácias de uma cidade do
}

\section{Sudoeste da Bahia}

\author{
Rapid Testing for COVID-19 in a pharmacy chain in a city in the Southwest of Bahia \\ Pruebas rápidas de COVID-19 en una cadena de farmacias en una ciudad del suroeste de Bahía
}

Recebido: 07/12/2021 | Revisado: 11/12/2021 | Aceito: 12/12/2021 | Publicado: 21/12/2021

\author{
Leonardo Pereira Santos \\ ORCID: https://orcid.org/0000-0001-6700-248X \\ Faculdade Independente do Nordeste, Brasil \\ E-mail: leonardopereirasantosleo7@gmail.com \\ Antonio Carlos Ricardo Braga Junior \\ ORCID: https://orcid.org/0000-0001-5870-4527 \\ Universidade Federal da Bahia, Brasil \\ E-mail: braga.ufba@hotmail.com \\ Aline Teixeira Amorim \\ ORCID: https://orcid.org/0000-0003-2597-8665 \\ Faculdade Independente do Nordeste, Brasil \\ E-mail: aline.amorim2011@hotmail.com
}

\begin{abstract}
Resumo
O vírus transmissor da COVID-19 foi descoberto em casos de pneumonia viral em Wuhan (China), em 2019, e foi denominado de SARS-CoV-2 pela Organização Mundial de Saúde (OMS), em 12 de janeiro de 2020. Pertence a uma grande família de vírus constituídos de RNA individual positivo encadeado com um envelope, cuja proteína $\mathrm{N}$ (Nucleocapsídeo), geralmente conservada entre os $\beta$-coronavírus, é usada constantemente como instrumento de diagnóstico para COVID-19. O Med Test Coronavírus (COVID-19) Ag (Teste Rápido) tem por finalidade a detecção, de forma qualitativa, à presença do vírus, já o Med Test Coronavírus (COVI-19) IgG/IgM (Teste Rápido) tem o propósito de revelar anticorpos IgG e IgM para COVID-19. O presente estudo tem como objetivo geral descrever o perfil dos resultados obtidos na testagem rápida para COVID-19 em uma rede de farmácias com filiais em uma cidade do sudoeste da Bahia. Tratou-se de uma pesquisa de campo, a qual contou com a participação indireta de 241 pessoas com as quais foram realizados testes, com idade entre 18 e 60 anos. Os resultados foram comparados posteriormente com os sintomas relatados pelos pacientes por intermédio de um questionário empregado antes da efetivação de cada teste. Assim, com a realização de ambos os testes, a comparação dos resultados e os sintomas descritos pelos pacientes, foi obtida uma relação entre resultado do teste, sintoma e idade do paciente. Diante dos resultados, verificou-se que pacientes que apresentaram sintomas de febre e perda de paladar foram mais associados com a positividade do teste de antígeno, e o sintoma de dor de garganta apresentou uma menor correlação com a positividade para o mesmo teste. Foi possível verificar a presença de positividade para COVID-19 em pacientes assintomáticos, e a importância de realizar os testes de antígeno e anticorpo no tempo devido.
\end{abstract}

Palavras-chave: COVID-19; Farmácia; Testes diagnósticos para COVID-19.

\begin{abstract}
The virus that spreads the COVID-19 was discovered in cases of viral pneumonia in Wuhan (China), in 2019, and was named SARS-CoV-2, by the World Health Organization (WHO) on January 12, 2020. The virus belongs to a large family of viruses consisting of individual positive RNA connected with an envelope, it has an N (Nucleocapsid) protein, generally conserved among $\beta$-coronaviruses, constantly used as a diagnostic tool for COVID-19. The MedTest Coronavirus (COVID-19) Ag (Rapid Test) is intended to qualitatively detect the presence of the virus, and the MedTest Coronavirus (COVID-19) IgG/IgM (Rapid Test) has the purpose of detecting IgG antibodies and IgM for COVID-19. The present study aimed to describe the profile of the results obtained in the rapid testing for COVID-19 in a pharmacy chain with branches in a city in the Southwest of Bahia, Brazil. This was a field research, with the indirect participation of 241 people who took the tests, aged between 18 and 60 years. The results were collected and compared later with the symptoms reported by the patients through a questionnaire applied before each test. Thus, by performing the two tests, and comparing the results with the symptoms described by the patients, a relationship between the test result, symptom and patient age was obtained. Based on the results, it was found that patients who presented symptoms of fever and loss of taste were more associated with the positivity of the antigen test, and the symptom of sore throat had a lower correlation with the positivity for the same test. It was possible to verify the
\end{abstract}


presence of positivity for COVID-19 in asymptomatic patients, and the importance of performing the antigen and antibody tests in due time.

Keywords: COVID-19; Pharmacy; Diagnostic tests for COVID-19.

\begin{abstract}
Resumen
El virus causador de la COVID-19 fue detectado en casos de neumonía viral en Wuhan (China) en 2019 y nombrado SARS-CoV-2 por la Organización Mundial de la Salud (OMS) en 12 de enero de 2020. Pertenece a una gran familia de virus, está constituido de ARN de cadena sencilla, polaridad positiva y envoltura, poseé proteína Nucleocápside $(\mathrm{N})$, generalmente conservada entre los betacoronavirus, constantemente utilizada como instrumento de diagnóstico para la COVID-19. El Med Test Coronavirus (COVID-19) Ag (Test Rápido) tiene por finalidad detectar cualitativamente la presencia del virus, y el Med Test Coronavirus (COVID-19) Igc/IgM (Test Rápido) tiene el propósito de desvelar anticuerpos IgG e IgM para COVID-19. El presente estudio tiene como objetivo general describir el perfil de los resultados obtenidos en el testeo rápido de COVID-19 en una red de farmacias con filiales en una ciudad del suroeste de Bahia, Brasíl. Se trató de una investigación de campo que contó con la participación indirecta de 241 personas que realizaron las pruebas, con edades entre 18 y 60 años, para que se recopilaran los resultados y se les compararan con los síntomas informados por los pacientes en un cuestionario aplicado antes de cada testeo. A través de la realización de los test y de la comparación de los resultados con los síntomas informados, se obtuvo una relación entre resultados del test, los síntomas y la edad del paciente. Con base en los resultados, se encontró que los pacientes que presentaban síntomas de fiebre y pérdida del gusto estaban más asociados con la positividad de la prueba de antígeno, y el síntoma de dolor de garganta tenía menor correlación con la positividad de la misma prueba. Se pudo constatar la presencia de positividad para COVID-19 en pacientes asintomáticos y la importancia de realizar las pruebas de antígenos y anticuerpos a su debido tiempo.
\end{abstract}

Palabras clave: COVID-19; Farmacia; Pruebas de diagnóstico para COVID-19.

\title{
1. Introdução
}

O coronavírus pertence a uma grande família de vírus constituído de RNA individual positivo envolto por um envelope. A proteína central do SARS-CoV-2 é a proteína N (nucleocapsídeo), componente proteico localizado dentro do vírus. Essa proteína é relativamente conservada entre os $\beta$-coronavírus e é frequentemente usada como uma ferramenta para o diagnóstico de coronavírus. O ACE2, um dos principais receptores para o SARS-CoV-2 entrar nas células, é altamente significante para a pesquisa do mecanismo de infecção viral, segundo Uzunian (2020). Outros vírus pertencentes à família são causas conhecidas de doenças graves, como a Síndrome Respiratória do Oriente Médio (MERS) e a Síndrome Respiratória Aguda Grave (SARS) (Brasil, 2014; Werneck \& Carvalho, 2020). Segundo Lana et al. (2020), o novo vírus conhecido como SARS-CoV-2 foi descoberto em casos de pneumonia viral em Wuhan (China), em 2019, o qual foi denominado oficialmente pela Organização Mundial de Saúde (OMS), em 12 de janeiro de 2020, responsável por desenvolver a doença do novo coronavírus, conhecida como COVID-19. No Brasil, o primeiro caso confirmado de COVID-19, segundo o Ministério da Saúde (MS), foi registrado no dia 26 de fevereiro de 2020 (Brasil, 2020).

De acordo com Lana et al. (2020), desde que foi declarado pela Organização Mundial de Saúde (OMS), em 30 de janeiro de 2020, como um surto, a doença causada pelo novo coronavírus (COVID-19) se tornou uma emergência de saúde pública internacional. Após em 11 de março de 2020, a COVID-19 foi caracterizada pela OMS como uma pandemia, ou seja, uma doença com propagação rápida e em escala mundial.

A transmissão do coronavírus pode ocorrer por gotículas de saliva, espirro, tosse ou catarro que podem ser repassados por toque ou aperto de mão, objetos ou superfícies contaminadas pelo infectado. Assim, o diagnóstico precoce de novos casos de COVID-19, por meio da testagem, tornou-se crucial para interromper a disseminação do vírus, somado a estratégias de isolamento social e medidas de higiene, até que vacinas efetivas e eficazes se tornassem disponíveis para a população (Magno et al., 2020).

O teste mais indicado para o diagnóstico da COVID-19 é a Proteína C-reativa (PCR) em tempo real, sendo considerado como padrão ouro por conta de sua alta sensibilidade e especificidade, empregado para identificar se uma pessoa está com a doença no momento, mediante detecção do material genético do vírus. É realizado por meio de um swab (tipo de 
cotonete grande), que é introduzido no nariz e/ou garganta do paciente, quando há suspeita de infecção, e realizado preferencialmente na primeira semana de sintomas. Contudo, o teste PCR em tempo real é realizado em laboratórios especializados, o que além de restringir o acesso, demanda uma maior especialização para sua realização, como descreve Magno et al. (2020). Dessa forma, a Agência Nacional de Vigilância Sanitária (ANVISA) autorizou a utilização de testes rápidos em farmácias para auxiliar no diagnóstico do COVID-19 em farmácias comerciais no Brasil por meio da publicação da Resolução de Diretoria Colegiada (RDC) da Anvisa n 377/2020, evento importante para traçar o panorama da propagação da COVID-19.

Essa autorização foi feita em caráter temporário e excepcional, devido à situação emergencial de saúde pública internacional relacionada à COVID-19. Para isso, farmácias com licença sanitária e autorização de funcionamento promoveram a realização de testes rápidos (ensaios imunocromatográficos) para a pesquisa de anticorpos ou antígeno do novo coronavírus (SARS-CoV-2), sem fins de diagnóstico confirmatório. Essa medida entrou em vigor em 29 de abril de 2020 , com vigência até o reconhecimento pelo Ministério da Saúde de que não mais se caracteriza a situação de Emergência em Saúde Pública de Importância Nacional declarada pela Portaria GM/MS n 188/2020, segundo o Conselho Regional de Farmácia do Estado de São Paulo (CRFSP, 2021).

O MedTeste Coronavírus (COVID-19) Ag (Teste Rápido) detecta qualitativamente a presença do antígeno de COVID-19 em amostras de swab nasofaríngeo, cuja finalidade é fornecer resultados em 10 minutos. O teste utiliza anticorpos específicos para o novo Coronavírus para detectar seletivamente a proteína do Nucleocapsídeo (N) do novo Coronavírus (SARS-CoV-2) nas amostras de swab nasofaríngeo (Grupo BR MED, 2021). O MedTest Coronavírus (COVID-19) IgG/IgM (Teste Rápido) é um imunoensaio cromatográfico rápido para a detecção qualitativa dos anticorpos IgG e IgM para COVID-19 em sangue total, soro ou plasma como auxílio ao diagnóstico de infecções primárias e secundárias pelo novo Coronavírus (Grupo BR MED, 2021). Dessa forma, detectam a infecção de forma indireta, medindo a resposta imune do hospedeiro à infecção. As amostras devem ser obtidas, em geral, a partir do oitavo dia do início dos sintomas, de modo que seja garantido o tempo necessário para o sistema imunológico produzir anticorpos em quantidade suficiente para detecção (Lima et al., 2020).

Os testes rápidos para COVID-19 Ag e $\mathrm{IgG} / \mathrm{IgM}$, realizados em farmácias, são de suma importância para ampliar o acesso da população à testagem, com isso, diminuir a sobrecarga, principalmente nos hospitais e laboratórios, bem como contribuir para a contenção do vírus. Assim, o objetivo do presente trabalho é descrever o perfil dos resultados obtidos na testagem rápida para COVID-19 em uma rede de farmácias com filiais em uma cidade do sudoeste da Bahia, para tanto, foi feita a correlação entre a sintomatologia e as comorbidades dos pacientes com os resultados obtidos nos testes.

\section{Metodologia}

O estudo apresentou uma pesquisa de caráter descritivo, com o objetivo de determinar a distribuição de condições relacionadas à saúde, segundo o tempo, o lugar e/ou as características dos indivíduos (Lima-Costa; Barreto, 2003). Também apresentou a natureza retrospectiva, pois foram colhidas informações pregressas dos fatores de exposição e acompanhamento, por um período de tempo, dos indivíduos (Camargo et al., 2019). Além disso, a investigação foi quantitativa, pois foram coletados dados numéricos sobre variáveis (Esperón, 2017).

Para isso, foi realizada uma análise da quantidade de testes rápidos para detecção de antígeno e de anticorpos COVID19 no período entre 06 julho de 2021, até 28 de agosto de 2021, correlacionando os achados com os sintomas, sexo e idade relatados pelos pacientes. A pesquisa ocorreu em uma das filiais de uma Rede de Farmácias, localizada em uma cidade do Sudoeste da Bahia. Foram analisadas as respostas de 241 pacientes, com idade entre 18-60 anos, provenientes do Questionário de Notificação para Teste Covid-19, preenchido no momento da consulta com o farmacêutico da unidade. Pacientes com idade 
inferior a 18 ou superior a 60 anos, ou com dados incompletos foram excluídos do presente estudo. A pesquisa foi aprovada pelo Comitê de ética e Pesquisa sob número de protocolo 4930618.

As respostas do Questionário de Notificação para Teste Covid-19 continham informações como: sintomatologia, idade, sexo, resultados dos testes de antígeno e anticorpo, bem como período de sintomatologia e presença de comorbidades. Os dados obtidos por meio dos questionários foram transcritos para a plataforma Excel, versão 2010 Microsoft ® e exportado para o software SPSS Statistics (Versão 24.0). Com a finalidade de organizar e obter um resumo conciso dos dados, foi utilizada estatística descritiva como análise de frequências, cálculos de medidas de tendência central como média, bem como de medidas de dispersão como desvio padrão (DP).

Também foram realizadas análises inferenciais. Para isso, foi utilizado o modelo de regressão logística e calculou-se a razão de chances (odds ratio - OR) e respectivos intervalos de confiança de 95\% (IC 95\%). A seleção das variáveis foi feita pelo método stepwise com método backward e os OR não ajustados e ajustados foram demonstrados no modelo final. A qualidade do ajuste foi verificada pelo teste de Hosmer-Lemeshow. Por fim, apenas variáveis com valor de p menor que 0,05 ou relevantes para a equação final foram utilizadas no modelo final. Para todas as análises foi adotado um nível de significância de $5 \%$.

\section{Resultados}

Foram analisados os resultados dos testes de 241 pacientes, sendo $111(46,1 \%)$ do sexo masculino e $130(53,9 \%)$ do sexo feminino, com idade entre 18 e 60 anos, de modo que foi obtida uma média de idade geral de 36 anos (DP 11,4), sendo 35,9 (DP 11,0) anos para o sexo masculino e 36,1 (DP 11,8) anos para o sexo feminino.

De acordo com a Tabela 1 , foi verificado que 30 pacientes $(12,4 \%)$, tomaram a 1a dose de vacina, 11 pacientes $(4,6 \%)$ tomaram também a 2a dose de vacina, 9 pacientes $(3,7 \%)$ não tomaram vacina e 191 pacientes $(79,3 \%)$ não informaram se tomaram ou não tomaram a vacina. Também foi verificado que 154 pacientes $(63,9 \%)$ apresentavam algum sintoma, já 87 pacientes $(36,1 \%)$ não apresentaram nenhum tipo de sintomas. Dentre os sintomas informados foi verificado que a coriza foi o mais relatado por 108 pacientes (19,5\%). É possível verificar que o dia de sintomas em que se teve a maior procura por consulta para realização dos testes foi o $4^{\circ}$ dia, com 45 pacientes (29,2\%). A descrição de comorbidades foi confirmada por 27 pacientes $(11,2 \%)$, com maior prevalência para a hipertensão, relatada por 16 pacientes $(59,3 \%)$.

O Med Test Coronavírus (COVID-19) Ag (Teste Rápido) foi realizado em 229 pacientes (95,0\%), com resultado positivo em 34 pacientes (14,9\%), enquanto o Med Teste Coronavírus IgG/ IgM (Teste Rápido) foi realizado em 13 pacientes $(5,4 \%)$ com os seguintes resultados: $\operatorname{IgG}$ e IgM, 2 pacientes (15,4\%); IgG positivo e IgM negativo, 1 paciente (7,7\%); e $\operatorname{IgG}$ e IgM negativos, 10 pacientes (76,9\%). Foi encontrada positividade em 2 pacientes (15,4\%) com IgG e IgM positivos, e 1 paciente $(7,7 \%)$ com IgG positivo e IgM negativo, de um total de 13 pacientes $(5,4 \%)$ que realizaram o teste Med Teste Coronavírus IgG/IgM (Tabela 1). É importante ressaltar que 10 pacientes assintomáticos que procuraram a farmácia para realização do teste rápido apresentaram positividade em um dos testes, dos quais 8 pacientes $(9,9 \%)$ positivo para o teste de antígeno ( $\mathrm{Ag})$ e 2 pacientes $(33,3 \%)$ positivo para o teste de anticorpo ( $\mathrm{IgM} / \mathrm{IgG})$ (de 6 realizados). 
Tabela 1: Informações gerais coletadas das fichas de anamnese dos pacientes atendidos na farmácia. N=241 pacientes.

\begin{tabular}{|c|c|c|}
\hline Informação do questionário & $\mathbf{n}$ & $\%$ \\
\hline \multicolumn{3}{|l|}{ Tomou vacina? } \\
\hline Sim, 1 dose & 30 & 12,4 \\
\hline Sim, 2 doses & 11 & 4,6 \\
\hline Não tomou & 9 & 3,7 \\
\hline Não informado & 191 & 79,3 \\
\hline \multicolumn{3}{|l|}{ Apresentou sintomas? } \\
\hline Sim & 154 & 63,9 \\
\hline Não & 87 & 36,1 \\
\hline \multicolumn{3}{|l|}{ Quais sintomas? } \\
\hline Dor de garganta & 94 & 17,0 \\
\hline Dispneia & 15 & 2,7 \\
\hline Febre & 42 & 7,6 \\
\hline Tosse & 99 & 17,9 \\
\hline Dor de cabeça & 90 & 16,2 \\
\hline Diarreia & 12 & 2,2 \\
\hline Dor no corpo & 39 & 7,0 \\
\hline Perda de paladar & 26 & 4,7 \\
\hline Perda do olfato & 29 & 5,2 \\
\hline Coriza & 108 & 19,5 \\
\hline \multicolumn{3}{|l|}{ Presença de 1 ou mais sintomas } \\
\hline 0 & 87 & 36,1 \\
\hline 1 & 14 & 5,8 \\
\hline 2 & 35 & 14,5 \\
\hline 3 & 25 & 10,4 \\
\hline 4 & 39 & 16,2 \\
\hline 5 & 18 & 7,5 \\
\hline 6 & 16 & 6,6 \\
\hline 7 & 4 & 1,7 \\
\hline 8 & 2 & 0,8 \\
\hline 9 & 1 & 0,4 \\
\hline 10 & 0 & 0 \\
\hline
\end{tabular}

Dias de sintomas ao realizar a consulta

$\begin{array}{ccc}2^{\text {o }} & 3 & 1,9 \\ 3^{\circ} & 37 & 24,0 \\ 4^{\text {o }} & 45 & 29,2 \\ 5^{\text {o }} & 34 & 22,1 \\ 6^{\circ} & 24 & 15,6 \\ 7^{\text {o }} & 5 & 3,2 \\ 8^{\text {o }} & 2 & 1,3 \\ 9^{\text {o }} & 1 & 0,6 \\ 10^{\text {o }} & 2 & 1,3 \\ 15^{\text {o }} & 1 & 0,6\end{array}$

$\begin{array}{ccc}\text { Apresentava comorbidades? } & & \\ \text { Sim } & 27 & 11,2 \\ \text { Não } & 214 & 88,8\end{array}$

Quais comorbidades?

$\begin{array}{ccc}\text { Hipertensão } & 16 & 59,3 \\ \text { Gestante } & 2 & 7,4 \\ \text { Diabetes } & 2 & 7,4 \\ \text { Obesidade } & 1 & 3,7 \\ \text { Asma } & 5 & 14,8 \\ \text { Doença cardíaca } & 1 & 3,7\end{array}$




\begin{tabular}{|c|c|c|}
\hline Informação do questionário & $\mathbf{n}$ & $\%$ \\
\hline Hipertireoidismo & 1 & 3,7 \\
\hline \multicolumn{3}{|l|}{ Realizou teste de antígeno? } \\
\hline Sim & 229 & 95,0 \\
\hline Não & 12 & 5,0 \\
\hline \multicolumn{3}{|l|}{ Resultado do teste de antígeno } \\
\hline Positivo & 34 & 14,9 \\
\hline Negativo & 195 & 85,2 \\
\hline \multicolumn{3}{|l|}{ Realizou teste de anticorpo? } \\
\hline Sim & 13 & 5,4 \\
\hline Não & 228 & 94,6 \\
\hline \multicolumn{3}{|l|}{ Resultado do teste de anticorpo } \\
\hline IgG E IgM positivos & 2 & 15,4 \\
\hline IgG positivo e IgM negativo & 1 & 7,7 \\
\hline IgG e IgM negativo & 10 & 76,9 \\
\hline \multicolumn{3}{|l|}{ Assintomático com positividade em um dos testes } \\
\hline Antígeno (de 81 realizados) & 8 & 9,9 \\
\hline Anticorpo IgM/IgG positivos (de 6 realizados) & 2 & 33,3 \\
\hline Acumulado (Antígeno + Anticorpo) & 10 & 11,5 \\
\hline
\end{tabular}

Fonte: Dados da pesquisa (2021).

De acordo com os dados da Tabela 2 e Figura 1, observa-se que os dias de sintomas relatados pelos pacientes em que houve maior procura pela realização dos testes, ficou compreendido entre o $3^{\circ}$ e o $6^{\circ}$ dia, assim como o teste que foi realizado: o de antígeno. Isso contribui para avaliar se os testes foram realizados de acordo com período sintomatológico mais indicado. Foi verificado que 2 testes de Antígeno (Ag) foram realizados fora do período recomendado, ou seja, foram realizados no $8^{\circ}$ e no $10^{\circ}$ dia de sintomas, assim como a realização de 2 testes de Anticorpo ( $\left.\operatorname{IgG} / \operatorname{IgM}\right)$ no $4^{\circ}$ e no $5^{\circ}$ dia de sintomas

Tabela 2: Descrição dos dias de sintomas relatados de acordo com o teste realizado em pacientes atendidos em uma unidade da Rede de Farmácias em um município do sudoeste baiano. N=241.

\begin{tabular}{ccc}
\hline Dias de sintoma & $\begin{array}{c}\text { Teste de Antígeno } \\
\text { n }(\%)\end{array}$ & $\begin{array}{c}\text { Teste de Anticorpo } \\
\text { n (\%) }\end{array}$ \\
\hline $2^{\circ}$ & $3(1,30 \%)$ & $0(0,00 \%)$ \\
$3^{\circ}$ & $37(16,20 \%)$ & $0(0,00 \%)$ \\
$4^{\circ}$ & $45(19,70 \%)$ & $1(8,30 \%)$ \\
$5^{\circ}$ & $33(14,50 \%)$ & $1(8,30 \%)$ \\
$6^{\circ}$ & $23(10,10 \%)$ & $0(0,00 \%)$ \\
$7^{\circ}$ & $5(2,20 \%)$ & $0(0,00 \%)$ \\
$8^{\circ}$ & $1(0,40 \%)$ & $1(8,30 \%)$ \\
$9^{\circ}$ & $0(0,00 \%)$ & $1(8,30 \%)$ \\
$10^{\circ}$ & $1(0,40 \%)$ & $1(8,30 \%)$ \\
$15^{\circ}$ & $0(0,00 \%)$ & $1(8,30 \%)$ \\
Sem sintomas & $80(35,10 \%)$ & $6(50,00 \%)$ \\
\hline
\end{tabular}

Fonte: Dados da pesquisa (2021). 
Figura 1: Testes realizados por dia de sintoma em pacientes atendidos em uma unidade da Rede de Farmácias em um município do sudoeste baiano.

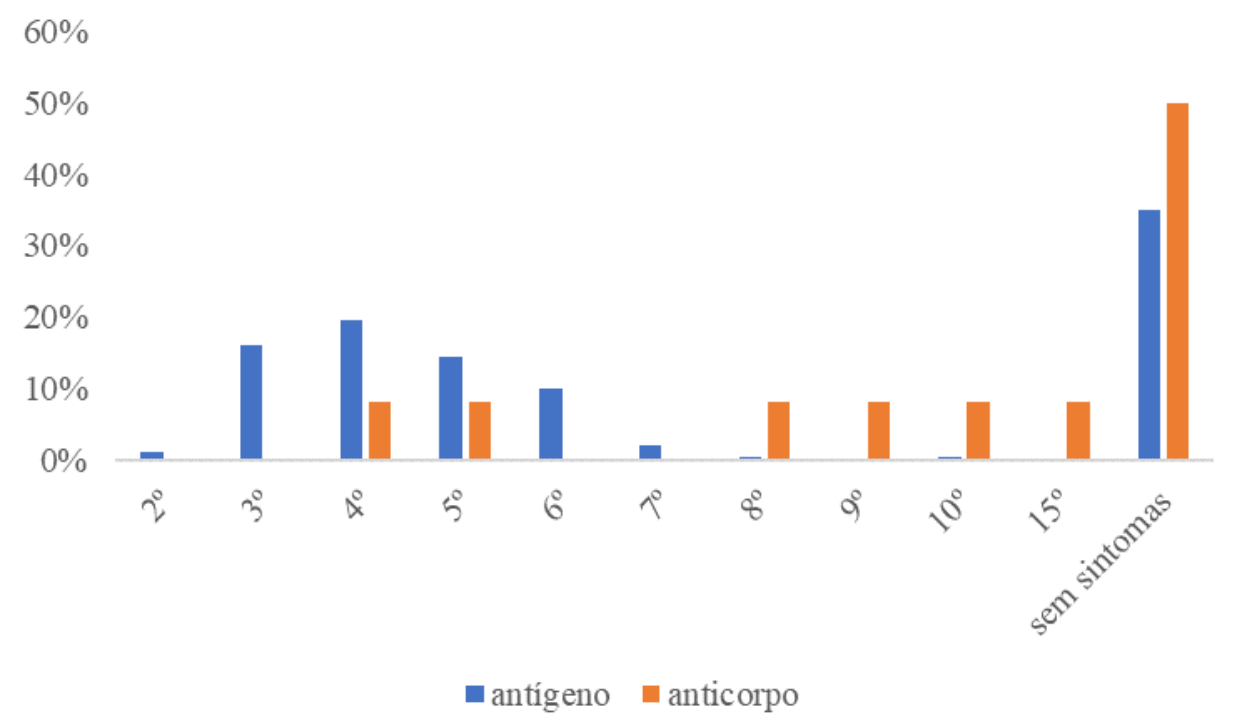

Fonte: Dados da pesquisa (2021).

Foi avaliado se existe correlação entre sexo, idade e a presença de sintomas relatados pelos pacientes e a positividade com o teste de antígeno e anticorpos. Não houve diferença estatisticamente significante entre sexo e idade média e os resultados para os testes de antígeno e anticorpo. Os sintomas relatados pelos pacientes foram dor de garganta, dispneia, febre, tosse, dor de cabeça, diarreia, dor no corpo, faltar de paladar, falta de olfato e coriza. Não houve associação entre os sintomas apresentados e a positividade no teste de anticorpos. Para o teste de antígenos, após ajuste na regressão logística, os sintomas de febre, perda de paladar e de dor de garganta apresentaram correlação com o desfecho do teste. Assim, pacientes com febre apresentaram um risco 4,9 (IC 95\% 1,832-13,127) vezes maior do que pacientes que não apresentaram febre de apresentar positividade no teste de antígeno; pacientes com perda de paladar apresentaram um risco 6,7 vezes (IC 95\% 2,382-18,837) maior de apresentar positividade do teste de antígeno quando comparados com pacientes que não apresentaram esse sintoma. Contudo, pacientes com dor de garganta apresentaram um risco 0,203 menor (IC 95\% 0,071-0,581) de ser positivo no teste de antígeno quando comparado com pacientes com outros sintomas (Tabela 3). 
Tabela 3: Sintomas relacionados com a positividade no teste de antígeno.

\begin{tabular}{|c|c|c|c|c|c|c|c|c|}
\hline \multirow[t]{2}{*}{ Sintomas ${ }^{\text {a. }}$} & \multicolumn{2}{|c|}{$\begin{array}{c}\text { Resultado Teste } \\
\text { Antígeno } \\
\end{array}$} & \multirow{2}{*}{$\begin{array}{c}\mathbf{P} \\
(\text { Wald })\end{array}$} & \multirow{2}{*}{$\begin{array}{l}\text { Razão de } \\
\text { chances }\end{array}$} & \multirow{2}{*}{ IC $95 \%$} & \multirow{2}{*}{$\begin{array}{l}P(\text { Wald }) \\
\text { ajustado }\end{array}$} & \multirow{2}{*}{$\begin{array}{l}\text { Razão de } \\
\text { chances } \\
\text { ajustado }\end{array}$} & \multirow{2}{*}{$\begin{array}{l}\text { IC } 95 \% \\
\text { ajustado }\end{array}$} \\
\hline & $\begin{array}{l}\text { Positivo } \\
\text { N }(\%)\end{array}$ & $\begin{array}{c}\text { Negativo } \\
\mathbf{N}(\%)\end{array}$ & & & & & & \\
\hline \multicolumn{9}{|l|}{ Febre } \\
\hline Sim & $13(38,2)$ & $26(13,3)$ & 0,008 & 4,431 & $1,465-13,402$ & 0,002 & 4,904 & $1,832-13,127$ \\
\hline Não & $21(61,8)$ & $169(86,7)$ & & 1 & & & 1 & \\
\hline \multicolumn{9}{|c|}{ Perda de paladar } \\
\hline Sim & $12(35,3)$ & $13(6,7)$ & 0,046 & 3,731 & $1,026-13,565$ & $<0,0001$ & 6,699 & $2,382-18,837$ \\
\hline Não & $22(64,7)$ & $182(93,3)$ & & 1 & & & 1 & \\
\hline \multicolumn{9}{|c|}{ Dor de garganta } \\
\hline Sim & $9(26,5)$ & $81(41,5)$ & 0,002 & 0,164 & $0,053-0,507$ & 0,003 & 0,203 & $0,071-0,581$ \\
\hline Não & $25(73,5)$ & $114(58,5)$ & & 1 & & & 1 & \\
\hline \multicolumn{9}{|l|}{ Dor no corpo } \\
\hline Sim & $11(32,4)$ & $28(14,4)$ & 0,117 & 2,499 & $0,796-7,853$ & 0,066 & 2,676 & $0,937-7,642$ \\
\hline Não & $23(67,6)$ & $167(85,6)$ & & 1 & & & 1 & \\
\hline
\end{tabular}

a. Sintomas que permaneceram na equação final da regressão. A qualidade do ajuste foi avaliada pelo teste de Hosmer-Lemershow ( $\mathrm{p}=0$, 570). Fonte: Dados da pesquisa (2021).

\section{Discussão}

Alguns países da Ásia e da Oceania apresentaram controle da pandemia com a combinação de estratégias com a ampla testagem. Na China, por exemplo, algumas medidas foram importantes para o controle da COVID-19, como a detecção precoce de casos por intermédio da testagem, isolamento dos casos e rastreio de todos os contactantes, além de atendimento clínico de qualidade para os infectados (Magno et al., 2020). Magno et al. (2020) explicam, também, que apesar de não esgotar a literatura sobre a resposta da testagem dos países, ressalta-se a importância das estratégias de testagem associadas à organização do sistema de saúde no enfrentamento à pandemia, pois o número de casos confirmados permite o monitoramento da progressão da doença, o que pode evitar o colapso da rede de atenção hospitalar, em função da articulação entre distintos níveis da atenção à saúde.

O teste padrão ouro para testagem do SARS-CoV-2 é a detecção do material genético do vírus obtido por swab combinado oral/nasal, detectando-se o RNA viral por PCR em tempo real (RT-q PCR). No entanto, existem alguns aspectos limitantes desse teste, como: 1) a positividade desse teste ocorre geralmente nos primeiros 4 a 8 dias após o aparecimento dos sintomas, usualmente tornando-se negativo após cerca de 14 dias; 2) trata-se de teste de alta complexidade técnica, que necessita de uma infraestrutura com um nível de biossegurança adequada para realização, e é relativamente caro (Magno et al., 2020). Assim, os testes rápidos se tornam uma alternativa como uma ferramenta de triagem rápida, contribuindo para desafogar os hospitais e aumentar a acessibilidade da população à testagem para a COVID-19 (Sinha \& Balayla, 2020).

Nesse estudo, visamos compreender o perfil dos pacientes que procuraram atendimento nas farmácias para a testagem rápida para a COVID-19. Verificou-se que a população feminina buscou mais atendimento do que homens. Estudos demonstram que enquanto homens e mulheres têm a mesma prevalência de COVID-19, os pacientes do sexo masculino têm uma mortalidade mais alta por COVID-19 (Jin et al., 2020). Dessa forma, campanhas estimulando a testagem deveriam ser difundidas para esse público alvo.

Com relação à idade, observou-se nesse estudo que pacientes que buscaram os estabelecimentos para a testagem 
tinham idade em torno de 39 anos. Apensar de pacientes com mais de 60 anos apresentar maior risco de desenvolver formas graves da doença (Jin et al., 2020), nenhum paciente com mais de 60 anos foi testado positivo neste estudo, o que pode ser justificado também pela baixa procura desse público aos estabelecimentos. Contudo, uma proporção elevada e sustentada da incidência de COVID-19 está presente entre adultos jovens (idade 18-39). Além disso, vale ressaltar que 10 pacientes (11,5\%) assintomáticos testaram positivo no presente estudo, sendo que 8 pacientes $(9,9 \%)$ para Ag (de 81 realizados) e 2 pacientes $(33,3 \%)$ para $\operatorname{IgM} / \operatorname{IgG}$ (de 6 realizados). Dessa forma, cabe ressaltar a importância da testagem nesse grupo de pacientes, pois mesmo não manifestando nenhum sintoma, apresentam papel na disseminação da doença durante a epidemia, criando um possível reservatório de doença com risco de afetar os mais vulneráveis, como os idosos ou aqueles que apresentam comorbidades (Malmgren et al., 2021).

No presente estudo foi observada uma maior prevalência de pacientes testados com hipertensão. Estudos apontam que pessoas idosas e com comorbidades como hipertensão, Diabetes Mellitus, doenças pulmonares crônicas e outras, tem maior probabilidade de desenvolver uma infecção grave pela Covid-19 assim como também possuem maior probabilidade de evoluir para o óbito, sendo assim, são considerados grupos de risco (Wu et al., 2020). A presença de múltiplos problemas crônicos de saúde parece estar inter-relacionados com a patogênese da COVID-19, fato também observado em endemias prévias por outros coronavírus (MERS e SARS). Apesar da evolução clínica não ser clara, estudos têm demonstrado relação direta e importante da faixa etária do paciente e a sua carga de morbidades (número e gravidade) com o aumento do risco para a incidência de desfechos clínicos desfavoráveis, tais como internação hospitalar, necessidade de unidade tratamento intensivo (UTI) e óbito (Nunes et al., 2020).

Vieira et al. (2020) explicam que as manifestações clínicas de COVID-19 podem ser desde totalmente assintomáticas (em até $89 \%$ dos infectados) ou caracterizarem-se por sintomas discretos, até críticos e fatais. Os sintomas podem se desenvolver entre 2 a 14 dias após exposição ao vírus, com um período médio de incubação de 5,1 dias, por isso, o período recomendado de quarentena ser, habitualmente, 14 dias. Dentre os sintomas relatados pelos pacientes, a coriza obteve maior prevalência com 108 pacientes $(19,5 \%)$, porém, os sintomas de febre e perda de paladar estiveram associados em maior número com a positividade para teste $\mathrm{Ag}$ com 13 pacientes (38,2\%) e 12 pacientes (35,3\%), respectivamente. O estudo de Costa et al. (2020) revela que a combinação da perda do olfato, paladar e febre teve um valor preditivo positivo de $61,7 \%$. Os resultados do estudo sugerem que a perda de paladar/olfato é um forte preditor de infecção pelo SARS-CoV-2.

Outro ponto crítico a ser levado em consideração é que a efetividade da testagem para a presença de antígeno ou de anticorpo contra COVID-19 depende do tempo de infecção e sintomatologia (CDC, 2021; Wise, 2021). Quanto à relação acerca dos dias de início dos sintomas com o teste correto a ser realizado, Lima et al. (2020) explicam que a reação em cadeia de polimerase com transcrição reversa (RT-PCR) foi considerado método-padrão de referência para confirmação da infecção, o qual deve ser realizado no período igual ou inferior aos primeiros 7 dias do início dos sintomas para a detecção do ácido nucleico do vírus SARS-CoV-2 no escarro, esfregaço de garganta e secreções das amostras do trato respiratório inferior. Já os ensaios de anticorpos por imunoenzimáticos e imunocromatográficos detectam, de forma indireta, a infecção, visto que mede a resposta imune do hospedeiro à infecção, desde que a amostra seja obtida a partir do oitavo dia do início dos sintomas, tempo necessário para que o sistema imunológico produza anticorpos suficientes para detecção.

Ainda não é possível afirmar, com clareza, o papel dos testes rápidos sorológicos para o diagnóstico individual, uma vez que o resultado não reativo não afasta a possibilidade de infecção por SARS-CoV-2, e também a presença de falsos positivos inerentes a qualquer teste. Contudo, no contexto da saúde pública, para o uso em inquéritos sorológicos populacionais, demonstra-se sua elevada aplicabilidade (Vieira et al., 2020), tornando-se ferramenta estratégia fundamental para o aumento na detecção de novos casos de COVID-19. A descentralização da testagem utilizando os testes rápidos permite ampliar o cuidado à população, bem como promover o melhoramento da vigilância epidemiológica, uma vez que as 
desigualdades econômicas entre as localidades, a falta de distribuição de equipamentos e infraestrutura necessária para diagnóstico por RT-PCR acabam inviabilizando o diagnóstico preciso e o acompanhamento epidemiológico. Assim, iniciativas que visaram a ampliação de testagem, a diminuição de aglomerações em unidades hospitalares, bem como a contribuição para o diagnóstico mais preciso foram adotadas pela Agência Nacional de Vigilância Sanitária (ANVISA), destacando-se a aprovação da aplicação de testes rápidos em farmácias (Magno et al., 2020; Oliveira et al., 2020). Dessa forma, as farmácias se tornaram importantes pontos de apoio à saúde durante a pandemia (CFF, 2020).

\section{Considerações Finais}

Diante dos resultados, foi possível verificar a presença de positividade para COVID-19 em pacientes assintomáticos, o que mostra a importância da pesquisa do SARS-CoV-2 nesse grupo de pacientes, os quais, mesmo não apresentando sintomas, podem transmitir o vírus. A realização do teste, seja Antígeno (Ag) ou Anticorpo ( $\operatorname{IgG} / \operatorname{IgM}$ ), no intervalo de dias de sintomas não recomendado, pode interferir no resultado do paciente com um falso positivo ou falso negativo.

Outro resultado constatado foi que os sintomas de febre e perda de paladar estão mais associados com a positividade do teste Med Teste Coronavírus Ag, também, que o sintoma de dor de garganta apresenta uma menor positividade para o mesmo teste.

Por fim, é possível identificar e compreender que a testagem rápida para COVID-19, em farmácias comerciais, é de grande importância para a saúde pública, pois contribui diretamente com o fechamento do diagnóstico do paciente, bem como descongestiona e diminui a carga dos hospitais que também realizam testes para COVID-19. Verifica-se uma grande contribuição para a ciência, na pesquisa e no controle epidemiológico, com a notificação dos casos positivos na plataforma eSUS e na atualização dos boletins diários dos municípios em que os pacientes residem.

Assim, estudos futuros que visam realizar um levantamento dos sinais e sintomas dos pacientes que buscaram atendimento nas farmácias para diagnóstico da COVID-19, cruzando esses dados com comorbidades e o diagnóstico utilizando os testes rápidos, contribuirão para ampliar o entendimento de como a pandemia se comportou em diferentes regiões, favorecendo a elaboração de estratégias epidemiológicas e reforçando o papel das farmácias como estabelecimentos de saúde atuantes no combate à pandemia.

\section{Referências}

Brasil, Ministério da Saúde. (2014). Informe Técnico - MERS-CoV (Novo Coronavírus). https://portalarquivos2.saude.gov.br/images/pdf/2014/junho/10/Infor me-Tecnico-para-Profissionais-da-Saude-sobre-MERS-CoV-09-06-2014.pdf.

Camargo, L. M. A., Silva, R. P. M. \& Meneguetti, D. U. L. (2019). Tópicos de metodologia de pesquisa: Estudos de coorte ou cohorte prospectivo e retrospectivo. J. Hum. Growth Dev., 29(3), 433-436, http://pepsic.bvsalud.org/scielo.php?script=sci_arttext\&pid=S0104$12822019000300016 \& \operatorname{lng}=$ pt\&nrm=iso.

CDC - Center for Disease control and Prevention (2021) Interim Guidance for Antigen Testing for SARS-CoV-2. https://www.cdc.gov/coronavirus/2019ncov/lab/resources/antigen-tests-guidelines.html\#print

Cespedes, M. S. \& Souza, J. C. R. P. (2020). SARS-CoV-2: uma revisão para o clínico. Scielo, 1-04, https://preprints.scielo.org/index.php/scielo/pre print/view/26/41

CFF - Conselho Federal de Farmácia. (2020). Pandemia fortalece conceito de "nova farmácia" pós-covid. 2020. https://www.cff.org.br/noticia.php?id=6083 CRFSP - Conselho Regional de Farmácia do Estado de São Paulo. (2020). Testes rápidos para COVID-19 em farmácias - CRF-SP. http://www.crfsp.org.br/noticias/11285-testes-r\%C3\%A1pidos.html

Costa, K. V. T. da et al. (2020). Olfactory and taste disorders in COVID-19: a systematic review. Brazilian Journal Of Otorhinolaryngology. 86(6), 790. http://dx.doi.org/10.1016/j.bjorl.2020.05.008.

Esperón, J. M. T. (2017). Pesquisa Quantitativa na Ciência da Enfermagem. Esc Anna Nery 2017;21(1):e20170027 https://www.scielo.br/j/ean/a/6c6QJ6BLDW3YRjFzfXwMMkC/?format=pdf\&lang=pt

Grupo BR MED. (2021). Teste rápido COVID-19. https://www.grupobrmed.com.br/covid19 
Research, Society and Development, v. 10, n. 17, e51101724441, 2021

(CC BY 4.0) | ISSN 2525-3409 | DOI: http://dx.doi.org/10.33448/rsd-v10i17.24441

Jin, J.M et al. (2020). Gender Differences in Patients With COVID-19: Focus on Severity and Mortality. Frontiers in public health, 8 , 152. https://doi.org/10.3389/fpubh.2020.00152

Lana, R. M. et al. (2020). Emergência do novo coronavírus (SARS-CoV-2) e o papel de uma vigilância nacional em saúde oportuna e efetiva. Cadernos de Saúde Pública, 36(3), 1-5, FapUNIFESP (SciELO). http://dx.doi.org/10.1590/0102-311x00019620.

Lima, F. E. T et al. (2020). Intervalo de tempo decorrido entre o início dos sintomas e a realização do exame para COVID-19 nas capitais brasileiras, agosto de 2020. Epidemiol. Serv. Saude, 30(1), 1-10, 4://dx.doi.org/10.1590/s1679-49742021000100021.

Lima-Costa, M. F \& Barreto, S.M. (2003). Tipos de estudos epidemiológicos: conceitos básicos e aplicações na área do envelhecimento. Epidemiologia e Serviços de Saúde, 189-201, http://dx.doi.org/10.5123/s1679-49742003000400003.

Magno, L. et al. (2020). Desafios e propostas para ampliação da testagem e diagnóstico para COVID-19 no Brasil. Ciência \& Saúde Coletiva, 25(9), 33563359,). http://dx.doi.org/10.1590/1413-81232020259.17812020.

Malmgren J., Guo, B. \& Kaplan, H. G. (2020) Continued proportional age shift of confirmed positive COVID-19 incidence over time to children and young adults: Washington State. PLoS ONE. 16(3): e0243042. https://doi.org/10.1371/journal.pone.0243042

Nunes, B. P. et al. (2020). Multimorbidade e população em risco para COVID-19 grave no Estudo Longitudinal da Saúde dos Idosos Brasileiros. Cadernos de Saúde Pública, 36(12), 2-2 https://scielosp.org/article/csp/2020.v36n12/e00129620/pt/.

Oliveira, L. M. S. et al. (2020). Estratégia de enfrentamento para covid-19 na atenção primária à saúde: relato de experiência em Salvador-BA. Revista Gaúcha de Enfermagem, 42, 2-2, http://dx.doi.org/10.1590/1983-1447.2021.20200138.

Sinha, N. \& Balayla, G. (2020). Sequential battery of COVID-19 testing to maximize negative predictive value before surgeries. Revista do Colégio Brasileiro de Cirurgiões, 47, 5-5, https://www.scielo.br/j/rcbc/a/P3rkBwbK9M886sjbLB8tGzk/?lang=pt.

Uzunian, A. (2020). Coronavírus SARS-CoV-2 and Covid-19. Jornal Brasileiro de Patologia e Medicina Laboratorial, 56, 1-4, http://dx.doi.org/10.5935/1676-2444.20200053.

Vieira, L. M. F. et al. (2020). COVID-19 - Diagnóstico Laboratorial para Clínicos. Ciência \& Saúde Coletiva, 1(1), 05-12. https://preprints.scielo.org/index.php/scielo/preprint/download/411/513/512.

Werneck, G. L. \& Carvalho, M. S. (2020). A pandemia de COVID-19 no Brasil: crônica de uma crise sanitária anunciada. Cadernos de Saúde Pública, 36(5), 1-5 http://dx.doi.org/10.1590/0102-311x00068820.

Wise, J. (2020) Covid-19: Timing is critical for antibody tests, finds Cochrane review. BMJ 2020;369:m2584 http://dx.doi.org/10.1136/bmj.m2584

Wu, D., Wu, T., Liu, Q. \& Yang, Z. (2020). The SARS-CoV-2 outbreak: what we know: what we know. International Journal Of Infectious Diseases, 94, 4448, 12 http://dx.doi.org/10.1016/j.ijid.2020.03.004. 